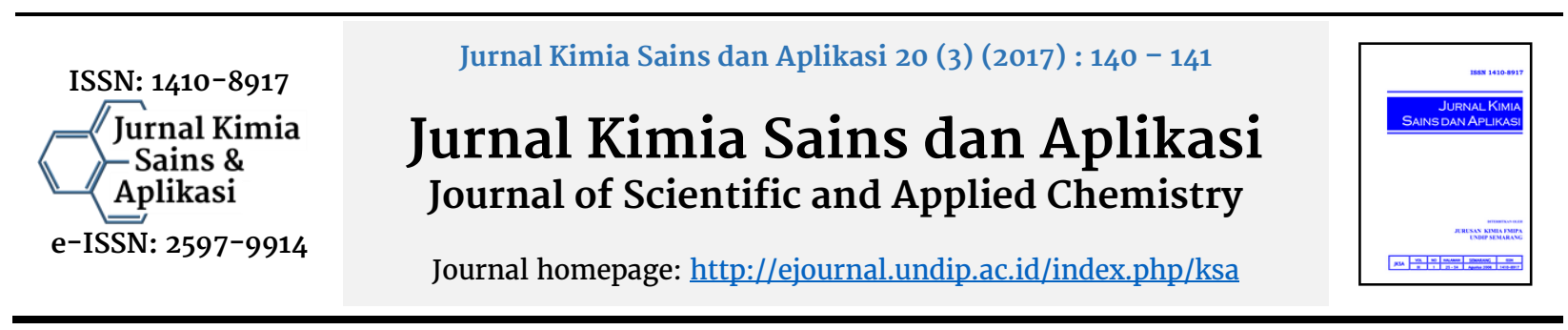

\title{
Perbandingan Penentuan Kadar Alumunium dalam Antasida Menggunakan Metode Spektrometri Tampak dengan Spektrometri Serapan Atom
}

\author{
Raharjo $^{\mathrm{a}^{*}}$ \\ a Pranata Laboratorium Pendidikan Kimia, Jurusan Kimia, Fakultas Sains dan Matematika, Universitas Diponegoro, Jalan Prof. \\ Soedarto, Tembalang, Semarang 50275
}

\section{Article Info}

Keywords: Aluminium, Visible spectrometry, atomic absorption spectrometry

\begin{abstract}
It has been done the comparation between visible spectometry and atomic absorption spectrometry (AAS) methods in aluminium determination. By AAS method, sample solution was analyzed directly. Whereas by visible spectrometry method, the sample firstly was extracted by 8-Hydroxyquinoline in chloroform, and than the alumunium determined. Absorbancy was measured with ultra violet - visible spectrometer at 408 $\mathrm{nm}$. The result of experiment show that the mean concentration of aluminium determined by AAS is $81.01 \pm 0.95 \mathrm{ppm}$ and by visible spectrometry is $79.70 \pm 1.64 \mathrm{ppm}$. Student's - t test yields texperiment 0.86 and table 2.31 ( $\mathrm{P}=95 \%)$. It can be concluded both methods are not significantly different because texperiment is less than $t_{\text {table. }}$
\end{abstract}

\section{Abstrak}

Telah dilakukan uji banding metode penentuan kadar alumunium secara spektrometri tampak dengan spektometri serapan atom (SSA). Penentuan kadar alumunium secara SSA dilakukan dengan menganalisis larutan sampel secara langsung, sedangkan analisis secara spektometri tampak dilakukan dengan perlakuan awal ekstrasi menggunakan pereaksi 8-hidroksikuinolin dalam kloroform. Absorbansi diukur dengan spektrometer ultra ungu - tampak pada panjang gelombang $408 \mathrm{~nm}$. Hasil penelitian menunjukkan konsentrasi rata - rata secara SSA adalah $81,01 \pm 0,95 \mathrm{ppm}$ dan secara spektrometri tampak adalah 79,70 $\pm 1,64 \mathrm{ppm}$. Hasil uji t-student menyatakan bahwa teksperimen sebesar 0,86 lebih kecil dari pada tabel yang besarnya 2,31 untuk $\mathrm{P}=95 \%$. Hal ini dapat disimpulkan bahwa kedua metode tersebut tidak berbeda secara nyata.

\section{Pendahuluan}

Aluminium adalah logam yang sangat ringan dan kuat, oleh karena itu digunakan untuk membuat kendaraan yang ringan. Demikian pula aluminium banyak digunakan dalam bangunan modern seperti bingkaijendela dan kerangka ruang perkantoran ${ }^{(1)}$.

Pada industri pesawat terbang aluminium digunakan sebagai pelapis badan pesawat karena mempunyai sifat anti korosi dan ringan serta mudah dibentuk $^{(2)}$.

Kandungan aluminium dalam suatu sampel dapat dianalisis dengan beberapa metode antara lain dengan metode spektrometri serapan atom dan spektrometri tampak.

Pada penentuan kadar aluminium secara spektrometri serapan atom larutan sampel langsung dianalisis oleh spektrometer, sedangkan analisis secara spektrometri tampak dilakukan dengan perlakuan awal ekstraksi sampel dengan pereaksi 8-hidroksikuinolin dalam kloroform. Proses ekstraksi dipengaruhi oleh keasaman larutan dan akan terbentuk kompleks aluminium-oksin yang larut dalam kloroform serta berwarna kuning. Absorbansi diukur dengan spektrometer ultra ungu - tampak pada panjang gelombang optimum(3). 
Untuk memperoleh keseksamaan hasil kedua metode tersebut maka perlu diadakan uji banding antar metode secara statistik dengan menggunakan uji tstudent.

\section{Metodologi penelitian}

Alat : Spektrometer serapan atom merk Perkin Elmer, Spektrometer ultra ungu - tampak V-200 merk LW scientic, Neraca analitik merk Adam, Stopwatch, pH meter,corong pisah dan perangkat gelas.

Bahan:

Larutan Sampel: sebanyak 10,395 g antasida dilarutkan dalam labu ukur $1000 \mathrm{~mL}$ yang berisi $15 \mathrm{~mL}$ $\mathrm{HCl}$ dan ditambahkan aquabides sampai tanda batas. Kemudian diambil sebanyak $20 \mathrm{~mL}$ untuk diencerkan menjadi $250 \mathrm{ml}$.

Larutan Bufer asetat: sebanyak $25 \mathrm{~g}$ amonium asetat dilarutkan dalam $70 \mathrm{~mL}$ aquabides den $5 \mathrm{~mL}$ asam asetat glasial kemudian ditambah aquabides mencapai $100 \mathrm{ml}$,.

Larutan Oksin: sebanyak 2 g 8-hidroksikuinolin dilarutkan dalam kloroform sampai $100 \mathrm{~mL}$

Larutan standar aluminium dengan konsentrasi 25, 40, 60, 80, dan 100 ppm.

\section{Eksperimen}

Metode spektrometri serapan atom larutan sampel langsung dianalisis dengan spektrometer serapan atom pada panjang gelombang 390,3 nm, kecepatan alir asetilen $2 \mathrm{~L} /$ menit dan kecepatan alir $\mathrm{N}_{2} \mathrm{O} 4 \mathrm{~L} /$ menit.

Metode spektrometri tampak: larutan sampel sebanyak $30 \mathrm{~mL}$ dicampur dengan $3 \mathrm{~mL}$ larutan bufer asetat. Kemudian campuran tersebut diekstraksi dengan $20 \mathrm{~mL}$ larutan oksin dan dikocok selama 2 menit. Fasa organik dipisahkan, disaring dan diukur absorbansinya pada $408 \mathrm{~nm}$ dengan pembanding latutan blanko. Prosedur yang lama dikerjakan pula untuk larutan standar ${ }^{(4)}$.

\section{Hasil dan Pembahasan}

Hasil yang diperoleh dalam penelitian ini disajikan dalam Tabel 1. Hasil tersebut menunjukkan bahwa $t_{\text {eksperimen }}$ lebih kecil daripada $t_{\text {tabel. }}$.

Tabel 1. Konsentrasi Aluminium yang dianalisis secara SSA dan Spektrometri tampak.

\begin{tabular}{ccc}
\hline \multirow{2}{*}{ No } & \multicolumn{2}{c}{ Al $(\mathrm{ppm})$} \\
& Metode AAS & Metode tampak \\
\hline 1 & 80,93 & 79,12 \\
2 & 81,32 & 79,12 \\
3 & 82,42 & 81,99 \\
4 & 79,93 & 77,69 \\
5 & 80,43 & 80,56 \\
& Purata $=81,01$ & Purata $=79,70$ \\
& SD $=0,95$ & SD $=1,64$ \\
& teksperimen $=0,85$ tabel $=2,31$ \\
\hline
\end{tabular}

Spektrometri tampak merupakan metode analisis berdasarkan absorpsi energi sinar tampak oleh molekul berwarna. Aluminium dapat membentuk senyawa kompleks berwarna kuning bila direaksikan dengan 8hidroksikuinolin atau oksin dengan membentuk aluminium oksinat. Oleh karena itu aluminium dapat dianalisis dengan metode spektrometri tampak dengan mengukur absorbansinya pada panjang gelombang optimum $408 \mathrm{~nm}$. Ekstraksi dengan pelarut kloroform diperlukan untuk memperoleh kadar aluminium oksinat sebanyak mungkin dan bebas dari interferensi logamlogam lain.

Spektrometri serapan atom juga merupakan metode analisis yang berdasarkan absorpsi energi sinar tetapi oleh atom-atom dalam keadaan dasar dan dalam fasa gas.Analisis aluminium dengan metode inidiaksanakan dengan bahan bakar campuran gas asetilen dan $\mathrm{N}_{2} \mathrm{O}$ agar diperoleh suhu yang sesuai untuk pembentukan gas atom dalam kondisi dasar sebelum menyerap energi sinar. Bahan bakar asetilen dan udara tidak dipilih karena suhu yang dihasilkan lebih rendah daripada suhu yang diperlukan aluminium untuk berubah dari senyawa menjadi gas atom.

\section{Kesimpulan}

Kadar aluminium dalam tablet antasida yang ditentukan secara SSA adalah 81,01 \pm 0,95 ppm sedangkan secara spektrometri tampak adalah 79,70 \pm 1,64 ppm. Uji statistic dengan $\mathrm{t}$-student menunjukkan $\mathrm{t}_{\text {eksperimen }} 0,85$ dant $_{\text {tabel } 2,31}$ dengan $\mathrm{F}=95 \%$, sehingga dapat disimpulkan bahwa kedua metode tidak berbeda secara nyata.

\section{Referensi}

Achmad H., (1992), Kimia Unsur dan Radiokimia. PT Citra Aditya Bakti, Bandung, halaman 122 - 123.

Farhial and Lawrence, (1952), Industrial Toxicology, $2^{\text {nd }}$ edition, The Williams and Wilkins Baltimore, p 10 11.

APHA, (1992), Standard Methodes for The Examination of Water and Waste Water, $8^{\text {ht }}$ edition, Washington DC, p IV.25 - IV.35.

Fries J. and Getrost H., (1975), Organic Reagents for Trace Analysis, E. Merck, Darmstadt. p 22 - 25.

Miller J.C. and Miller J.N., (1988), Statistics for Analytical Chemistry, $2^{\text {nd }}$ edition, John Willey \& Sons, New York, p $55-58$. 